\title{
PENGARUH PENGGUNAAN MEDIA POWERPOINT TERHADAP HASIL BELAJAR MATEMATIKA SISWA KELAS XII DI MAN PANDEGLANG
}

\section{Deni Pratidiana ${ }^{1}$}

\begin{abstract}
This study aimed to determine : 1) The difference between the outcomes of mathematics learning by using Powerpoint Media and without using Powerpoint Media in the third grade of MAN Pandeglang; 2 ) The difference between the mathematics learning outcomes of students who have high creativity and low creativity in the third grade of MAN Pandeglang; 3) The interaction of using instructional media and creativity on learning outcomes in the third grade of MAN Pandeglang. The research used quantitative approach with experimental method by using treatment by level $2 \times 2$ design.In this study, the population was all students in the third grade of MAN Pandeglang, totally 184 students, and the sample were 40 students. The study was conducted at MAN Pandeglang. The findings of the research were : 1) The test results of $Q_{\text {count }}>Q_{\text {table }}(17.95>2.86)$ So there was the influence of using media on student learning outcomes; 2 ) The Test results of $Q_{\text {count }}>Q_{\text {table }}(7.93>2.86)$ So there were influence of creative differences on student learning outcomes ; 3 ) The ANOVA test showed that the value of $F_{\text {hitung }}$ was 4.36 and the $F_{\text {table }}$ with $d f=0: 05$ was 4,11 . So there is an interaction between instructional media and creativity on the student learning outcomes. So there was difference in mathematics learning outcomes between using powerpoint media and without using powerpoint media on students who have low creativity.
\end{abstract}

\section{Keywords: Powerpoint Media, The Outcomes of Learning Mathematics}

ABSTRAK: Penelitian ini bertujuan untuk mengetahui: (1) Perbedaan hasil belajar matematika antara yang menggunakan media powerpoint dan tanpa media powerpoint; (2) Perbedaan hasil belajar matematika antara siswa yang mempunyai kreativitas tinggi dan kreativitas rendah; (3) Interaksi antara penggunaan media pembelajaran dan kreativitas terhadap hasil belajar matematika siswa kelas XII di MAN Pandeglang. Metode penelitian yang digunakan dalam penelitian ini yaitu metode eksperimen dengan desain treatment by level $2 \times 2$. Dalam penelitian ini populasinya adalah semua siswa kelas XII MAN Pandeglang yang berjumlah 184 siswa, sebagai sampel penelitian sebanyak 40 orang. Temuan penelitian ini adalah: 1) Hasil pengujian $Q_{\text {hitung }}>Q_{\text {tabel }}(17.95>2.86)$ jadi ada pengaruh antara penggunaan media terhadap hasil belajar siswa; 2) Hasil pengujian $Q_{\text {hitung }}>Q_{\text {tabel }}(7.93>2.86$ ) jadi ada pengaruh perbedaan kreativitas terhadap hasil belajar siswa; 3) Uji Anova menunjukkan bahwa nilai $F_{\text {hitung }}$ sebesar 4.36 dan $F_{\text {tabel }} 4.11$ dengan $\mathrm{df}=0.05$. Jadi ada interaksi antara media pembelajaran dan kreativitas terhadap hasil belajar siswa.

Kata Kunci: Media Powerpoint, Hasil Belajar Matematika

\footnotetext{
1Dosen Pendidikan Matematika, Universitas Mathla'ul Anwar Banten, Email: denipratidiana@gmail.com
} 


\section{PENDAHULUAN}

Dalam dunia pendidikan dan pembelajaran, peranan media tidak dapat di abaikan, sebagai salah satu komponen pembelajaran, media tidak bisa luput dari pembahasan sistem pembelajaran secara menyeluruh. Pemanfaatan media seharusnya merupakan bagian yang harus mendapatkan perhatian guru dalam setiap kegiatan pembelajaran. Namun kenyataan bagian inilah yang sering terabaikan dengan berbagai alasan. Alasan yang sering muncul antara lain terbatasnya waktu untuk membuat persiapan mengajar, sulit mencari media yang tepat, tidak tersedianya biaya dan lain-lain.

Sesungguhnya betapa banyak jenis media yang bisa dipilih, dikembangkan dan dimanfaatkan sesuai dengan kondisi waktu, biaya maupun tujuan pembelajaran yang dikehendaki. Setiap jenis media memiliki karakteristik tertentu yang perlu kita fahami, sehingga kita dapat memilih media yang sesuai dengan kebutuhan dan kondisi yang ada di lapangan.

Peranan media yang semakin meningkat ini sering menimbulkan kekhawatiran bagi guru. Namun sebenarnya hal itu tak perlu terjadi, seandainya kita menyadari betapa masih banyak dan beratnya peran guru yang lain. Memberikan perhatian dan bimbingan secara individual kepada siswa, merupakan tugas penting bagi guru yang terkadang kurang mendapat perhatian. Hal ini mungkin karena waktu yang ada telah banyak tersita untuk tugas menyajikan materi pelajaran. Kondisi semacam ini akan terus terjadi selama guru masih menganggap bahwa dirinya merupakan sumber belajar utama (apalagi satu-satunya sumber) bagi siswa. Padahal, jika guru bisa memanfaatkan berbagai media secara baik, maka guru dapat berbagi peran dengan media.

Hampir disemua sekolah menengah, mata pelajaran matematika menempati posisi yang unik dan sulit di pelajari. Matematika mempunyai posisi yang penting, diterapkan di hampir semua disiplin ilmu yang lain. Matematika juga menjadi salah satu mata pelajaran yang diujikan sebagai Ujian Akhir Nasional, dengan demikain menjadi salah satu mata pelajaran yang memberi kontribusi pada keberhasilan atau kegagalan siswa.

Disisi yang lain, sifat mata pelajaran matematika yang bersifat abstrak dan hirarkis menyebabkan tingkat kesulitan yang relatif tinggi pada siswa yang mempelajarinya. Kesulitan ini tampak pada indikator pencapaian hasil belajar yang relatif lebih rendah dibandingkan dengan mata pelajaran yang lain. Terlihat pada penggunaan media pembelajaran, guru cenderung menggunakan cara klasikal dalam penyampaian materi, yaitu penggunaan media pembelajaran yang hanya menggunakan white board, spidol, dan buku penunjang saja. Ini sangat tidak tepat bila diterampak pada situasi dimana siswa butuh refrest dalam hal suasana belajar.

Kemajuan teknologi, khususnya dalam bidang Teknologi Informasi dan Komunikasi (TIK) memberikan peluang yang besar dalam perencanaan dan rekayasa pembelajaran yang bersifat multi dimensi. Teknologi yang bersifat multi media ini memberi peluang bagi kita untuk melibatkan aspek audio-visual dalam kegiatan pembelajaran. Darmawan (2011: 8 ) mengungkapkan bahwa di bidang pendidikan, peran guru untuk mendidik peserta didik menjadi manusia yang selalu mengikuti perkembangan zaman tanpa meninggalkan akar budaya sangat penting dalam menentukan perjalanan generasi bangsa ini.

Dalam pengembangan kurikulum dewasa ini dimana dalam proses pembelajaran, guru di tuntut untuk dapat dan mampu melaksanakan proses pembelajaran yang bersifat student centered. Dalam proses pembelajaran seorang 
pendidik harus bisa merencanakan dan memanfaatkan media sesuai dengan tujuan dan materi pembelajaran karna itu termasuk ke dalam kemampuan profesional guru yang harus dimiliki, sehingga dapat menciptakan suasana belajar yang menyenangkan, agar peserta didik memiliki semangat dan kreatifitas yang tinggi.

Berdasarkan pengamatan pada saat observasi ke MAN Pandeglang, kegiatan belajar mengajar di kelas masih berpusat pada guru dan buku paket saja. Dalam mengajarkan mata pelajaran matematika yang berisi tentang rumus-rumus dan teorinya, guru hanya menggunakan metode ceramah, tanya jawab dan penugasan saja. Media yang digunakan adalah papan tulis dan alat yang digunakan adalah spidol dan kapur. Sementara dalam sekolah tersebut telah tersedia sarana dan prasarana yang dapat mendukung penggunaan media elektronik, yakni penggunaan komputer atau laptop serta infokus yang dapat digunakan sebagai media pembelajaran. Namun, guru tidak menggunakan media tersebut dengan alasan, mereka belum terlalu memahami bagaimana cara penggunaan media, sehingga mereka hanya menggunakan media papan tulis saja.

Ketika guru matematika menerangkan pelajaran dengan menggunakan media papan tulis, guru terkadang tidak memperhatikan keadaan murid-muridnya. Komunikasi yang terjadi antara guru dan siswa juga sangat jarang. Akibatnya banyak siswa yang sering mengantuk saat guru sedang menerangkan. Ketika keadaan ini terjadi, maka proses belajar-mengajar tidak kondusif lagi. Hal ini mengakibatkan banyak siswa yang menganggap proses pembelajaran termasuk matematika adalah mata pelajaran yang membosankan, monoton, dan kurang menyenangkan. Akibatnya, hasil belajar siswa khususnya pada bidang studi matematika menjadi rendah, dan banyak siswa yang tidak tuntas dalam bidang studi matematika tersebut. Berdasarkan data yang diperoleh dari daftar kumpulan nilai (DKN) siswa kelas XII, sebanyak $61 \%$ siswa atau 170 orang dari 280 orang tidak tuntas dalam bidang studi matematika dengan nilai KKM 63. Dari DKN tersebut, peneliti dapat menyimpulkan bahwa nilai matematika siswa kelas XII masih dapat dikatakan rendah.

Salah satu cara untuk meningkatkan hasil belajar siswa adalah melalui kegiatan belajar mengajar. Mengajar di kelas adalah salah satu tugas seorang guru, oleh karena itu seorang guru dituntut untuk professional dalam menjalankan tugasnya. Pada hakekatnya proses belajar merupakan komunikasi antara guru dan siswa dari keadaan belum mengerti menjadi mengerti. Proses komunikasi guru dalam menyampaikan materi pelajaran kepada siswa dengan tujuan agar pengetahuan dari guru dapat dimiliki oleh siswa. Komunikasi tidak akan berjalan tanpa bantuan sarana penyampai pesan atau media. Jadi sebagai alat bantu, media mempunyai fungsi mempermudah guru dalam menyampaikan materi dalam kegiatan belajar mengajar. Dengan menggunakan media pengajaran dalam proses belajar mengajar akan diperoleh manfaat, diantaranya pengajaran akan lebih menarik perhatian siswa dan materi pengajaran akan lebih dipahami oleh siswa.

Alternatif pemecahan masalah yaitu dengan memanfaatkan komputer sebagai media yang berbasis teknologi informasi dan komunikasi. Komputer dapat digunakan sebagai alat bantu dalam menyiapkan bahan ajar maupun dalam proses pembelajaran agar lebih efektif dan efisien. Software dalam komputer yang digunakan dalam pengembangan media pembelajaran ini adalah microsoft powerpoint.

Power point merupakan salah satu program aplikasi presentasi yang menyajikan teks, gambar, suara dan video secara jelas kepada siswa dan materi yang bersifat abstrak dapat diilustrasikan secara lebih menarik kepada siswa dengan berbagai 
gambar animasi yang dapat merangsang minat belajar siswa, sehingga siswa dapat lebih tertarik dalam mengikuti pelajaran matematika. Hasil observasi dan wawancara yang dilakukan peneliti, sarana yang berada di sekolah juga sangat mendukung dalam pemanfaatan media powerpoint, yakni dimana di sekolah MAN Pandeglang telah tersedia infokus dan Laptop.

Terkait dengan hal di atas, penulis merancang sebuah pembelajaran yang bersifat kontekstual yang disajikan dengan menggunakan teknologi informasi dan komunikasi. Pembelajaran dilakukan dengan menggunakan bantuan media pembelajaran yang dibuat dengan menggunakan aplikasi microsoft powerpoint. Menurut Ida (2010: 2) bahwa powerpoint merupakan salah satu aplikasi untuk menyusun presentasi. Microsoft powerpoint dipilih karena kesederhanaan dan kemudahan dalam mengoperasikannya. Dibandingkan dengan aplikasi yang lebih berat misalkan Macromedia Flash atau Dreamweaver, aplikasi tersebut relatif lebih dikenal oleh kalangan guru sekolah menengah pada umumnya.

\section{METODE PENELITIAN}

Dalam penelitian ini digunakan penelitian Kuantitatif. Menurut Sugiyono (2011: 11) bahwa metode kuantitaif dapat dibagi menjadi dua, yaitu metode eksperimen dan metode survei. Berdasarkan tujuan penelitian yang ingin di capai, maka metode yang digunakan adalah metode eksperimen. Menurut Sugiyono (2010: 11) bahwa metode penelitian eksperimen merupakan metode penelitian yang digunakan untuk mencari pengaruh treatment tertentu (perlakuan) dalam kondisi terkontrol. Rancangan dalam penelitian ini adalah menggunakan desain treatment $2 \times 2$. Dalam rancangan ini terdapat tiga variabel, yaitu variabel bebas, variabel moderator, variabel terikat. Penggunaan media powerpoint dilaksanakan di kelas eksperimen dan non powerpoint dilaksanakan di kelas kontrol, keduanya ditempatkan sebagai variabel bebas. Kreativitas dipilah menjadi dua tingkatan yaitu kreativitas tinggi dan kreativitas rendah dilaksanakan di kelas eksperimen dan kelas kontrol, keduanya ditempatkan sebagai variabel moderator. Sebagai variabel terikatnya dalam penelitian ini adalah hasil belajar matematika kelas XII MAN Pandeglang.

Tabel 1. Desain Penelitian

\begin{tabular}{ccc}
\hline & \multicolumn{2}{c}{ Media Pembelajaran (A) } \\
Kreativitas Siswa (B) & Powerpoint $\left(\mathrm{A}_{1}\right)$ & Non Powerpoint $\left(\mathrm{A}_{2}\right)$ \\
\hline Kreativitas Tinggi $\left(\mathrm{B}_{1}\right)$ & $\mathrm{A}_{1} \mathrm{~B}_{1}$ & $\mathrm{~A}_{2} \mathrm{~B}_{1}$ \\
Kreativitas Rendah $\left(\mathrm{B}_{2}\right)$ & $\mathrm{A}_{1} \mathrm{~B}_{2}$ & $\mathrm{~A}_{2} \mathrm{~B}_{2}$ \\
\hline
\end{tabular}

Populasi dalam penelitian ini adalah siswa kelas XII Madrasah Aliyah Negeri Pandeglang yang berjumlah 184 siswa. Berdasarkan informasi dari Kepala Sekolah dan Wakil Kepala Sekolah Bidang Akademik/Kurikulum bahwa seluruh kelas XII itu setara (homogen). Pengambilan sampel pada penelitian ini dengan menggunakan teknik random sampling pada siswa kelas XII MAN Pandeglang dengan alasan populasi yang dipilih menjadi sampel memiliki karakteristik yang sama, sehingga berpeluang sama untuk menjadi sampel. Menurut Prasetyo dan Miftahul (2012: 123) bahwa teknik ini dapat dipakai jika populasi dari suatu penelitian homogen. 
Anggota sampel yang dipilih dalam penelitian ini sebanyak 22\% dari 184 siswa sebanyak 40 siswa. Arikunto (2006:134) mengungkapkan bahwa apabila subjek kurang dari 100 lebih baik diambil semuanya, sehingga penelitiannya merupakan penelitian populasi. Tetapi, jika jumlah subjeknya besar, dapat diambil antara $10 \%-$ $15 \%$ atau $20 \%-25 \%$ atau lebih.

Tahap pengambilan sampel sebagai berikut :

a. Teknik acak sederhana (simple random sampling) digunakan untuk memilih secara acak siswa yang akan menjadi sampel pada penelitian berjumlah 40 siswa.

b. Dari 40 siswa secara acak diundi lagi untuk menentukan kelas menjadi kelas eksperimen dan kelas kontrol masing-masing 20 siswa.

c. Kelas eksperimen diberikan kegiatan belajar mengajar menggunakan media powerpoint, sedangkan kelas kontrol tidak menggunakan media powerpoint (konvensional)

Selanjutnya semua sampel diberikan tes kreativitas figural verbal untuk menentukan kreativitas siswa pada kelas eksperimen dan kelas kontrol. Kelas eksperimen terdiri dari 20 siswa, dipilih 10 siswa dengan kreativitas tinggi dan 10 siswa dengan kreativitas rendah. Hal ini juga dilakukan pada kelas kontrol yang terdiri dari 20 siswa, maka dipilih 10 siswa dengan kreativitas tinggi dan 10 siswa dengan kreativitas rendah.

Tabel 2. Proporsi Sampel Penelitian

\begin{tabular}{cccc}
\hline \multirow{2}{*}{ Kreativitas(B) } & \multicolumn{3}{c}{ Media Pembelajaran $(\mathrm{A})$} \\
& Powerpoint $\left(\mathrm{A}_{1}\right)$ & Non Powerpoint $\left(\mathrm{A}_{2}\right)$ & \\
\hline Kreativitas & 10 & 10 & 20 \\
Tinggi $\left(\mathrm{B}_{1}\right)$ & & & \\
Kreativitas & 10 & 10 & 20 \\
Rendah $\left(\mathrm{B}_{2}\right)$ & 20 & 20 & 40 \\
Total & & & \\
\hline
\end{tabular}

Teknik analisis data yang digunakan adalah teknik statistik deskriptif dan inferensial. Statistik deskriptif yaitu menguraikan berdasarkan persentase frekuensi. Teknik statistik deskriptif digunakan untuk mendeskripsikan data antara lain ratarata (mean), median, modus, standard deviasi (Sd) dan kecenderungan data. Teknik statistik inferensial digunakan untuk menguji hipotesis penelitian, di mana teknik inferensial yang akan digunakan adalah teknik analisis varians dua jalur (desain faktorial 2x2) dengan taraf signifikan 0,05. Sebelum Anava dua jalur dilakukan, terlebih dahulu ditentukan persyaratan analisis yakni persyaratan normalitas menggunakan rumus chi-kuadrat, sedangkan untuk uji persyaratan homogenitas menggunakan Uji F (Riduwan, 2010: 179).

\section{HASIL PENELITIAN DAN PEMBEHASAN}

Data hasil penelitian diperoleh melalui tes hasil belajar matematika sebagai variabel terikat $(\mathrm{Y})$ menggunakan bentuk tes pilihan ganda. Data hasil tes tersebut diformulasikan ke skala 100 dengan rumus : (skor yang diperoleh : 20) x 100. Data tes hasil belajar matematika sebagai variabel terikat (Y), seperti pada Tabel 3 berikut. 
Tabel 3. Data Hasil Penelitian

\begin{tabular}{ccccc}
\hline No & \multicolumn{2}{c}{ Kelas Eksperimen } & \multicolumn{2}{c}{ Kelas Kontrol } \\
& Kreativitas & Kreativitas & Kreativitas & Kreativitas \\
Tinggi & Rendah & Tinggi & Rendah \\
\hline 1 & 95 & 75 & 65 & 60 \\
2 & 85 & 70 & 60 & 55 \\
3 & 85 & 70 & 60 & 55 \\
4 & 85 & 70 & 60 & 55 \\
5 & 75 & 65 & 60 & 50 \\
6 & 75 & 65 & 50 & 50 \\
7 & 75 & 60 & 50 & 45 \\
8 & 75 & 60 & 50 & 45 \\
9 & 75 & 60 & 40 & 45 \\
10 & 75 & 60 & 40 & 30 \\
\hline
\end{tabular}

Berdasarkan rumusan masalah dan desain penelitian yang digunakan, maka deskripsi data dapat dikelompokkan menjadi

Tabel 4. Deskripsi Data Penelitian

\begin{tabular}{ccc}
\hline & $\left(\mathbf{Y A}_{\mathbf{1}} \mathbf{A}_{\mathbf{2}} \mathbf{)}\right.$ & $\mathbf{( Y B}_{\mathbf{1}} \mathbf{B}_{\mathbf{2}} \mathbf{)}$ \\
\hline Sampel (N) & 40 & 40 \\
Mean & 61.95 & 61.95 \\
Median & 59.75 & 59.75 \\
Mode & 55.9 & 55.9 \\
Standar Deviasi & 15.94 & 15.94 \\
Variance & 254.1 & 254.1 \\
Minimum & 30 & 30 \\
Maximum & 95 & 95 \\
Sum & 2480 & 2480 \\
\hline
\end{tabular}

Upaya untuk mengetahui perbedaan hasil belajar matematika terlebih dahulu dilakukan analisis terhadap persyaratan data. Dalam penelitian ini pengujian persyaratan analisis yang digunakan adalah uji normalitas dan uji homogenitas. Uji normalitas data dimaksud untuk mengetahui distribusi atau sebaran skor data penggunaan powerpoint di kelas eksperimen dan non powerpoint di kelas kontrol serta kreativitas tinggi dan rendah di kedua kelas. Uji normalitas dalam penelitian ini menggunakan rumus chi-kuadrat, dengan ketentuan data dikatakan berdistribusi normal jika $\mathrm{x}^{2}$ hitung lebih kecil dari $\mathrm{x}^{2}$ tabel $\left(\mathrm{x}^{2}{ }_{\text {hitung }}<\mathrm{x}^{2}\right.$ tabel $)$.

Tabel 5. Uji Homogenitas

\begin{tabular}{ccccc}
\hline Data & $\mathrm{N}$ & $\mathrm{X}^{2}$ hitung & $\mathrm{X}^{2}$ tabel & Kesimpulan \\
\hline & 40 & 2.1988744 & 7.815 & Normal \\
Tabel 5. & & & & \\
Uji & & & & \\
Normalitas & & & & \\
$\mathrm{A}_{1} \mathrm{~A}_{2}$ & & & & \\
$\mathrm{~B}_{1} \mathrm{~B}_{2}$ & 40 & 2.1988744 & 7.815 & Normal \\
\hline
\end{tabular}


Uji homogenitas dilakukan untuk mengetahui apakah sampel yang dipilih menjadi responden berasal dari kelompok yang sama. Artinya, harus diketahui kalau sampel yang diambil memiliki sifat-sifat yang sama atau homogen. Dalam penelitian ini uji homogenitas menggunakan uji $\mathrm{F}$ varians terbesar dibagi varians terkecil.

Tabel 6. Uji Homogenitas

\begin{tabular}{ccccc}
\hline Keterangan & $\mathrm{N}$ & $\mathrm{F}_{\text {hitung }}$ & $\mathrm{F}_{\text {tabel }}$ & Simpulan \\
\hline A1A2 & 40 & 1.229 & 2.165 & Homogen \\
B1B2 & 40 & 2.051 & 2.165 & Homogen \\
\hline
\end{tabular}

Uji Hipotesis dilakukan untuk mengetahui apakah hipotesis yang diajukan dalam penelitian ini diterima atau ditolak. Dalam penelitian ini digunakan analysis of varian (Anova) ganda/dua jalur. Berdasarkan hasil penelitian pada Tabel 1, Tabel 2, Tabel 3, Tabel 4, Tabel 5, dan Tabel 6 di atas kemudian dianalisis menggunakan Anova taraf signifikansi 0.05 dengan hasil hitung koefisien $\mathrm{F}_{\text {hitung }}$ sebagai berikut.

Tabel 7. Uji Anova

\begin{tabular}{lcccccc}
\hline $\begin{array}{c}\text { Sumber } \\
\text { Varian }\end{array}$ & $\begin{array}{c}\text { Jumlah } \\
\text { Kuadrat } \\
(\mathrm{JK})\end{array}$ & $\begin{array}{c}\text { Derajat } \\
\text { kebebasan } \\
(\mathrm{db})\end{array}$ & $\begin{array}{c}\text { Kuadrat } \\
\text { Rerata } \\
(\mathrm{KR})\end{array}$ & $\mathrm{F}_{\text {hitung }}$ & $\mathrm{F}_{\text {tabel }}$ & $\begin{array}{c}\text { Interpretasi } \\
\text { Hasil }\end{array}$ \\
\hline Baris (A) & 4622.5 & 1 & 4622.5 & 80.59 & 4.11 & Signifikan \\
$\begin{array}{l}\text { Kolom (B) } \\
\text { Interaksi }\end{array}$ & 902.5 & 1 & 902.5 & 15.73 & 4.11 & Signifikan \\
(AB) & 250 & 1 & 250 & 4.36 & 4.11 & Signifikan \\
Galat (D) & 2065 & 36 & 57.36111 & & & \\
Total & 7840 & 39 & & & & \\
\hline
\end{tabular}

Pada interaksi $(\mathrm{AB})$ nilai $\mathrm{F}_{\text {hitung }}>$ Ftabel, sehingga disimpulkan terdapat interaksi antara penggunaan media pembelajaran dan kreativitas. Karena terdapat interaksi maka perlu dilakukan uji lanjut menggunakan uji Tukey. Penggunaan Uji Tukey untuk membandingkan kelompok-kelompok dengan jumlah sampel yang sama besar (Purwanto, 2011: 205)

Tabel 8. Rerata Hasil Belajar Tiap Kelompok

\begin{tabular}{cccc}
\hline Sumber Varian & $\mathrm{A}_{1}$ & $\mathrm{~A}_{2}$ & $\mathrm{~B}_{\text {total }}$ \\
\hline $\mathrm{B}_{1}$ & 80 & 53.5 & 66.75 \\
$\mathrm{~B}_{2}$ & 65.5 & 49 & 57.25 \\
$\mathrm{~K}_{\text {total }}$ & 72.75 & 51.25 & 62 \\
\hline
\end{tabular}

Tabel 9. Uji Tukey

\begin{tabular}{ccccccc}
\hline Sumber Varian & $\mathrm{Xi}$ & $\mathrm{Xj}$ & $\mathrm{N}$ & $\mathrm{Q}_{\text {hitung }}$ & $\mathrm{Q}_{\text {tabel }}$ & Hasil \\
\hline$\mu \mathrm{A}_{1}-\mu \mathrm{A}_{2}$ & 72.75 & 51.25 & 40 & 17.95 & 2.86 & Signifikan \\
$\mu \mathrm{B}_{1}-\mu \mathrm{B}_{2}$ & 66.75 & 57.25 & 40 & 7.93 & 2.86 & Signifikan \\
\hline
\end{tabular}


1. Terdapat perbedaan hasil belajar matematika antara perlakuan menggunakan media powerpoint dan tanpa media powerpoint.

Kriteria penerimaan $\mathrm{H}_{0}$ menggunakan koefisien hitung $\mathrm{Q}$

a. Jika koefisien $\mathrm{Q}_{\text {hitung }}<\mathrm{Q}_{\text {tabel }}$ maka $\mathrm{H}_{0}$ diterima dan $\mathrm{H}_{1}$ ditolak

b. Jika koefisien $Q_{\text {hitung }}>\mathrm{Q}_{\text {tabel }}$ maka $\mathrm{H}_{0}$ ditolak dan $\mathrm{H}_{1}$ diterima

Hasil pengujian $Q_{\text {hitung }}>Q_{\text {tabel }}\left(17.95>2.86\right.$ ) maka $\mathrm{H}_{0}$ ditolak. Jadi secara signifikan ada pengaruh antara penggunaan media terhadap hasil belajar siswa. Dari hasil tersebut maka hipotesis penelitian $\left(\mathrm{H}_{1}\right)$ diterima dan terbukti kebenarannya.

2. Terdapat perbedaan hasil belajar matematika antara siswa yang mempunyai kreativitas tinggi dan siswa yang mempunyai kreativitas rendah.

Kriteria penerimaan $\mathrm{H}_{0}$ menggunakan koefisien hitung Q

a. Jika koefisien $\mathrm{Q}_{\text {hitung }}<\mathrm{Q}_{\text {tabel }}$ maka $\mathrm{H}_{0}$ diterima dan $\mathrm{H}_{1}$ ditolak

b. Jika koefisien $\mathrm{Q}_{\text {hitung }}>\mathrm{Q}_{\text {tabel }}$ maka $\mathrm{H}_{0}$ ditolak dan $\mathrm{H}_{1}$ diterima

Hasil pengujian $Q_{\text {hitung }}>Q_{\text {tabel }}(7.93>2.86)$ maka $\mathrm{H}_{0}$ ditolak. Jadi secara signifikan ada pengaruh perbedaan kreativitas terhadap hasil belajar siswa. Dari hasil tersebut maka hipotesis penelitian $\left(\mathrm{H}_{1}\right)$ diterima dan terbukti kebenarannya.

3. Terdapat interaksi antara penggunaan media pembelajaran dan kreativitas terhadap hasil belajar matematika.

Kriteria penerimaan $\mathrm{H}_{0}$ menggunakan koefisien hitung $\mathrm{F}_{\text {hitung }}$

a. Jika koefisien $\mathrm{F}_{\text {hitung }}>\mathrm{F}_{\text {tabel }}$ maka $\mathrm{H}_{0}$ ditolak dan $\mathrm{H}_{1}$ diterima

b. Jika koefisien $\mathrm{F}_{\text {hitung }}<\mathrm{F}_{\text {tabel }}$ maka $\mathrm{H}_{0}$ diterima dan $\mathrm{H}_{1}$ ditolak

Dari uraian tentang uji Anova di atas menunjukkan bahwa nilai $\mathrm{F}_{\text {hitung }}$ sebesar 4.36 dan $\mathrm{F}_{\text {tabel }} 4.11$ dengan $\mathrm{df}=0.05$, sehingga $\mathrm{H}_{1}$ diterima. Jadi secara signifikan ada interaksi antara media pembelajaran dan kreativitas terhadap hasil belajar siswa. Dari hasil tersebut maka hipotesis penelitian $\left(\mathrm{H}_{1}\right)$ diterima dan terbukti kebenarannya.

\section{KESIMPULAN}

Berdasarkan hasil penelitian dan pembahasan tentang pengaruh penggunaan media powerpoint dan kreativitas terhadap hasil belajar matematika dibandingkan dengan penggunaan media non powerpoint diperoleh simpulan sebagai berikut:

1. Terdapat perbedaan hasil belajar antara perlakuan menggunakan media powerpoint dan tanpa media powerpoint pada pelajaran matematika siswa kelas XII di MAN Pandeglang.

2. Terdapat perbedaan hasil belajar antara siswa yang mempunyai kreativitas tinggi dan siswa yang mempunyai kreativitas rendah pada pelajaran matematika siswa kelas XII di MAN Pandeglang.

3. Terdapat interaksi antara penggunaan media pembelajaran dan kreativitas terhadap hasil belajar matematika siswa kelas XII di MAN Pandeglang.

\section{DAFTAR PUSTAKA}

Arikunto, S. (2006). Prosedur Penelitian: Suatu Pendekatan Praktis Edisi Revisi VI. Jakarta: Rineka Cipta.

Darmawan, D. (2011). Teknologi Pembelajaran. Bandung: Remaja Rosda Karya. 
Prasetyo, B., \& Miftahul J. L. (2012). Metode Penelitian Kuantitatif: Teori dan Aplikasi. Jakarta: Rajawali Pers.

Purwanto M. N. (2011). Statistika untuk Penelitian. Yogyakarta: Pustaka Pelajar.

Riduwan. (2010). Metode dan Teknik Menyusun Tesis. Bandung: Alfabet.

Septiana, I., dkk. (2010). Shortcourse Series: Presentasi lebih kreatif dengan Microsoft Powerpoint 2010. Semarang: Wahana Komputer.

Sugiyono. (2010). Statistika Untuk Penelitian. Bandung: Alfabeta.

Sugiyono. (2011). Metode Penelitian Kombinasi Mixed Methods. Bandung: Alfabeta.

Warsita, B. (2008). Teknologi Pembelajaran: Landasan \& Aplikasinya. Jakarta: Rineka Cipta. 